\title{
Is Holistic Management Really Saving Patagonian Rangelands From Degradation? A Response to Teague
}

\author{
Andrés F. Cibils, Raúl J. Lira Fernández, Gabriel E. Oliva, and Juan M. Escobar
}

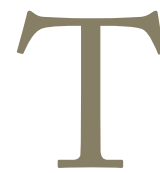

he application of the holistic management (HM) method in Patagonia was highlighted in Teague's ${ }^{1}$ rebuttal of the Briske et al. ${ }^{2}$ View Point recently published in Rangelands. Teague's ${ }^{1}$ letter reinforced Allan Savory's pictorial allusion to the Patagonia story in his now widely viewed TED talk. ${ }^{3}$ Since reference to the Patagonian cases in Teague ${ }^{1}$ was not supported by new or published evidence, and since we are familiar with many of these cases, we wish to provide a science-based perspective (complemented with firsthand knowledge) on Teague's ${ }^{1}$ and Savory's ${ }^{3}$ claims that $\mathrm{HM}$ grazing prescriptions are saving $\mathrm{Pa}-$ tagonian rangelands from continued degradation.

Teague states that,

range condition [was monitored] in detail for over 20 years on continuously grazed ranches in these dry rangelands. Every year the range condition was worse, so lowering the stocking rate even further [was advocated]. Deterioration did not stop, even in good years (p. 37). ${ }^{1}$

We found this statement particularly puzzling because it entirely ignores decades-worth of data from controlled grazing experiments ${ }^{4,5}$ conducted at two sites, each located a few miles away from ranches currently applying HM prescriptions. Both studies ${ }^{4,5}$ showed that range condition did not deteriorate under moderate continuous grazing. On the contrary, at one site, vegetation cover increased significantly (despite years of drought) and plant species diversity remained unchanged over the 10-year period of the study. At the second (drier) site, ${ }^{5} 5$ years of detailed vegetation measurements showed that pastures that had been grazed moderately for over 20 years exhibited no change in cover of both total vegetation or forage species, and no increase in bare soil. Teague's statement further contradicts a recently published long-term case study conducted on a continuously grazed ranch that adjusts stocking rates annually, tracking year-to-year fluctuations in forage availability. ${ }^{6}$ That study concluded that herbage production, stubble height of a key grass species, as well as sheep production indicators remained stable after 20 years of applying adaptive management based on moderate continuous grazing with flexible stocking rates. ${ }^{6}$

Teague also states that,

Five years ago they [an Argentine consulting firm that advocates $H M$ ] realized this [moderate continuous grazing?] was not succeeding, so using the example of successes in Argentina and other countries, they instituted Holistic Planned Grazing on scores of ranches in the region. After just three years, one of which was a drought year, [the] teams measured improvements in key ecosystem indicators and an improvement in animal performance, allowing for an increase in stock numbers [often five-fold] (p. 37). ${ }^{1}$

There is no mention here of which specific key indicators were measured and no details are provided about how these were determined. But more importantly, to offer 3 years of alleged data records (which often consist of decontextualized photographs) as proof that HM grazing prescriptions are reversing degradation of Patagonia's rangelands is at best misleading. Restoration of degraded rangelands in southern Patagonia requires the establishment of a keystone tussock species, a demographic process that has been shown to be extremely slow. ${ }^{7,8}$ Tussock recolonization events via seed establishment are rare $^{7}$ and management-induced local extinction of this species can take 37 to 84 years to fully unfold. ${ }^{8} \mathrm{Be}-$ cause of this, restoration is highly unlikely to occur in 3 years as claimed by Teague ${ }^{1}$ but more importantly, the legacies of ill-advised grazing strategies could influence this ecosystem's dynamics for decades if not centuries to come.

Grazing regimes similar to those promoted by the HM system, which homogenize both the landscape and the vertical grass canopy structure, have been shown to lead to less stable ranching systems that become more vulnerable to cli- 
mate-related livestock mortality risk. ${ }^{9}$ These risks are clearly illustrated by anecdotal testimonial evidence that we have gathered on some ranches in the region that have adhered to the HM system and show anything but improvement in animal performance as reported by Teague. ${ }^{1}$ For instance, a large corporate sheep ranching operation in Tierra del Fuego, Chile, that began applying HM grazing prescriptions lost at least 30,000 sheep (equivalent to a third of New Mexico's ewe population) in the winter months of 2010 and 2011 combined. Weaning rates in those years are said to have been at extremely low levels as well. Besides raising grave animal welfare concerns, massive losses such as those experienced by this ranch would have put any small-to-medium-sized family operation out of business. Another ranch on the Chilean Patagonian mainland that also applies HM prescriptions, and has been used as a regional demonstrator of this system's successes, reported weaning rates for 2013 that were 20 to 25 percentage points below the regional average.

We find no evidence to support the claim reproduced in Teague's letter ${ }^{1}$ that moderate continuous grazing promotes rangeland degradation in Patagonia. On the contrary, we have presented science-based evidence that supports the opposite $^{4-6}$ The ability of HM grazing schemes to curb degradation (as does moderate continuous grazing ${ }^{4}$ ) and furthermore to promote rangeland recovery in this region lacks evidence and is still being investigated on a handful of ranches in the region. The levels of risk associated with this management system appear to be extremely high; in at least one case, application of HM was associated with significant mortality. We are concerned that 10 years from now, when credible data to assess the alleged benefits of $\mathrm{HM}$ on Patagonian rangelands become available, consultants currently promoting this system will have moved on to other endeavors, and that ranchers who have been led to become enthused with this system will pay the price of applying high-risk strategies that lack evidence of their efficacy or true costs.

\section{References}

1. Teague, R. 2014. Deficiencies in the Briske et al. rebuttal of the Savory method. Rangelands 36(1):37-38.

2. Briske, D. D., B. T. Bestelmeyer, J. R. Brown, S. D. Fuhlendorf, And H. W. Polley. 2013. The Savory method cannot green deserts or reverse climate change: a response to the Allan Savory TED video. Rangelands 35(5):72-74.

3. Savory, A. 2013. How to green the world's deserts and reverse climate change. TED talks. Available at: http://www. ted.com/talks/allan_savory_how_to_green_the_world_s_ deserts_and_reverse_climate_change.html. Accessed 22 February 2014.

4. Oliva, G. E., A. F. Cibils, P. Borrelli, and G. Humano. 1998. Stable states in relation to grazing in Patagonia: a 10-year experimental trial. Journal of Arid Environments 40:113-131.

5. Buono, G., V. Massara Paletto, and D. Celdrán. 2011. Forage availability dynamics of a Patagonian steppe under different grazing use intensities by sheep. Revista Argentina de Producción Animal 31:135-143.

6. Oliva, G., D. Ferrante, S. Puig, and M. Williams. 2012. Sustainable sheep management using continuous grazing and variable stocking rates in Patagonia: a case study. Rangeland Journal 34:285-295.

7. Oliva, G., M. Collantes, and G. Humano. 2013. Reproductive effort and seed establishment in grazed tussock grass populations of Patagonia. Rangeland Ecology E Management 66:164-173.

8. Oliva, G., M. Collantes, and G. Humano. 2005. Demography of grazed tussock grass populations in Patagonia. Rangeland Ecology \& Management 58:466-473.

9. Cingolani, A. M., J. Anchorena, S. L. Stofella, And M. B. Collantes. 2002. A landscape-scale model for optimal management of sheep grazing in the Magellanic Steppe. Applied Vegetation Science 5:159-166.

Authors are Associate Professor of Range Science, Dept of Animal and Range Sciences, New Mexico State Univesity, Las Cruces, NM 88003, USA, acibils@nmsu.edu (Cibils); Research Animal Scientist, Instituto de Investigaciones Agropecuarias, Centro Regional de Investigación Kampenaike, Punta Arenas, Chile (Lira Fernández); Research Rangeland Ecologist, Instituto Nacional de Tecnologia Agropecuaria, Estación Experimental Santa Cruz, Rio Gallegos, Argentina (Oliva); and Research Rangeland Ecologist, Instituto Nacional de Tecnología Agropecuaria, Estación Experimental Chubut, Trelew, Argentina (Escobar).

Editor's Note: While these letters are unlikely to be the last word on this topic, they will be the last we publish in this exchange of Letters to the Editor prompted by the Briske et al. ${ }^{2}$ View Point. I welcome and encourage submission to Rangelands of future peerreviewed articles and View Points on the topic.

Rangelands 36(3):26-27

doi: 10.2111/Rangelands-D-14-00011.1

(c) 2014 The Society for Range Management 